\title{
Stimulation of Active and Passive Sodium Absorption by Sugars in the Human Jejunum
}

\author{
JOHN S. FORDTRAN \\ From the Gastroenterology-Liver Division of the Department of Internal \\ Medicine, The University of Texas Health Science Center at Dallas, South- \\ western Medical School, Dallas, Texas 75235
}

\begin{abstract}
A B S T R A C T The effects of glucose and fructose on water and sodium absorption in the human jejunum were compared to assess the relative contribution of active and passive sugar stimulation of sodium transport. The effect of fructose is assumed to be entirely passive, and the difference between the effects of fructose and glucose is assumed to be a measure of sugarstimulated, active sodium absorption. Water and sodium movement with mannitol was the base line. Three sets of test solutions with differing sugar concentrations were studied. Fructose stimulated $66-100 \%$ as much net sodium and water absorption as glucose. Fructose stimulated potassium absorption, whereas glucose stimulated potassium secretion. Urea absorption was stimulated by both sugars. Glucose and fructose stimulated sodium absorption when chloride was the major anion, but they had relatively little effect on net sodium movement when chloride was replaced by bicarbonate or sulfate.
\end{abstract}

It is concluded that glucose stimulates passive and active sodium transport in the human jejunum. Stimulated active sodium absorption generates an electrical potential across the mucosa that causes sodium (and potassium) secretion and partly or completely nullifies the effect of active sodium transport on net sodium movement. Net sodium absorption stimulated by glucose is mainly $(66-100 \%)$ the passive consequence of solvent flow. The accompanying anion determines the degree to which sugars stimulate sodium absorption $\left(\mathrm{Cl}>\mathrm{SO}_{4}>\mathrm{HCO}_{3}\right)$. The effects of bicarbonate and sugars on jejunal sodium absorption are not additive.

\section{INTRODUCTION}

Two mechanisms have been elucidated to explain glucose-stimulated sodium absorption in the intestine. The

Received for publication 17 July 1974 and in revised form 19 November 1974. first, derived mainly from short-circuited in vitro experiments (1-4), is that glicose and sodium interact with a common carrier in the brush border membrane; glucose stimulates the attachment of sodium to the carrier and thereby increases sodium entry into the cell. The sodium is removed from the cell by an active pump located on the lateral membrane. Enhanced sodium pumping increases net sodium absorption and generates a potential difference (serosal positive) across the mucosa (or increases the short-circuit current if the preparation is short-circuited). The second mechanism for glucose-stimulated sodium absorption, derived primarily from experiments carried out in vivo (5), is that glucose absorption stimulates water absorption and that water movement across the mucosa stimulates the passive absorption of sodium by solvent drag.

These two postulated mechanisms are not mutually exclusive, and in all likelihood both are correct. It is important, however, to establish the relative contribution that each plays in the stimulation of net sodium absorption by glucose in the human intestine. The problem is basic to an understanding of how the small intestine absorbs the 120-140 meq of sodium delivered to it after each meal (6) and how oral solutions containing glucose reduce water and sodium losses in severe diarrheal diseases such as cholera (7).

In the present paper the carrier interaction and solvent drag components of sugar-stimulated sodium absorption have been evaluated by comparing the effects of mannitol, fructose, and glucose on jejunal absorption of water, sodium, potassium, and urea. Mannitol is a nonabsorbable solute, and water and electrolyte movement with mannitol forms a base line for quantitating the effects of fructose and glucose. Urea and potassium are markers for passive movement of noncharged and charged solutes, respectively $(5,8)$. Fructose is rapidly absorbed by carrier-mediated diffusion. However, fructose does not stimulate active sodium absorption, 
and the fructose carrier does not react with sodium $(9,10)$. Fructose-stimulated absorption of sodium is therefore assumed to be passive, secondary to solvent drag. The difference between the effects of glucose and fructose is a measure of the active carrier interaction component of glucose-stimulated absorption. This assumption implies that the products of glucose and fructose metabolism within the intestinal mucosa have the same osmotic effectiveness, so that the absorption of $1 \mathrm{~mol}$ of glucose and fructose would result in the same solvent drag. Data of Holdsworth and Dawson (11) and Cook (12) suggest that the error resulting from metabolic degradation would be negligible.

To determine the role of the anion that accompanies sodium, the effects of glucose and fructose were measured with sodium chloride, sodium bicarbonate, and sodium sulfate. These experiments were prompted by the previous observation that substitution of bicarbonate for chloride enhances sodium absorption $(5,13)$ and by the desire to learn if the stimulatory effects of sugars and bicarbonate on sodium absorption are additive.

All of these experiments were carried out in the jejunum, since in man, glucose and bicarbonate increase net sodium absorption only in the proximal small intestine (5). In the human ileum glucose increases the potential difference across the mucosa but has no effect on net sodium absorption $(5,14-16)$.

\section{METHODS}

Normal subjects were studied with the triple-lumen perfusion system as previously described (5). Polyethylene glycol was the nonabsorbable volume marker. The infusion aperture was at the ligament of Treitz, and the proximal and distal aspiration sites were located 10 and $30 \mathrm{~cm}$ distally. The different test solutions were infused at appropriate rates (between 10 and $15 \mathrm{ml} / \mathrm{min}$ ) so that the mean flow rate and solute concentrations would be equal in the test segment, regardless of the rate of net water absorption or secretion with the various sugars and electrolytes (5). A 30-min equilibration period preceded the collection of samples; each study period lasted $1 \mathrm{~h}$. Collections from the proximal aspirating site began and ended $10 \mathrm{~min}$ earlier than collections from the distal site, in accord with the mean transit time of fluid through a $20-\mathrm{cm}$ segment of proximal jejunum. Two to four test solutions were studied in each subject, depending on the number of variables in a particular experiment. The order of infusion of different test solutions was randomized.

Samples were analyzed for polyethylene glycol, electrolytes, glucose, fructose, mannitol, and urea by methods that have been previously described $(5,13,14,16)$. Absorption rates were calculated from the perfusion rate, the change in concentration of the nonabsorbable marker, and the change in concentration of the test substance. Results are expressed as mean $\pm \mathrm{SE}$ and were analyzed statistically by means of paired $t$ test. Solute and water movements have dimensions of milliliters, milliequivalents, microequivalents, millimoles, or micromoles per hour per $20 \mathrm{~cm}$ of jejunum. For convenience, the intestinal segment length will be omitted when results are given in the text.

\section{RESULTS}

Effect of mannitol, glucose, and fructose on water and sodium (chloride) movement

$130 \mathrm{mM}$ glucose and fructose. Three test solutions containing $80 \mathrm{mM}$ sodium chloride and either $130 \mathrm{mM}$ glucose, fructose, or mannitol were perfused in nine subjects, and the results are shown in Table I, part A. Absorption rates of the sugars were $0.4 \mathrm{mmol} / \mathrm{h}$ for mannitol, $35 \mathrm{mmol} / \mathrm{h}$ for glucose, and $19 \mathrm{mmol} / \mathrm{h}$ for fructose. With the solution containing mannitol, sodium was secreted at a rate of $7.4 \mathrm{meq} / \mathrm{h}$. With the glucose solution, sodium was absorbed at a rate of $4.2 \mathrm{meq} / \mathrm{h}$, whereas with the fructose solution, sodium was secreted at a rate of $0.9 \mathrm{meq} / \mathrm{h}$. The difference in the rate of sodium movement with glucose and mannitol and between fructose and mannitol is equal to the quantity of sodium absorption stimulated by these two sugars, designated $\Delta \mathrm{Na}$ in Table I. Stimulated sodium absorption was $11.6 \mathrm{meq} / \mathrm{h}$ with glucose and $6.5 \mathrm{meq} / \mathrm{h}$ with fructose. Dividing these values by the quantity of sugar absorbed gives the stimulated sodium absorption rate per millimole of sugar absorbed: $0.32 \mathrm{meq} / \mathrm{mmol}$ for glucose and $0.35 \mathrm{meq} / \mathrm{mmol}$ for fructose. By a similar series of calculations, stimulated water absorption rates were 5.5 and $5.7 \mathrm{ml} / \mathrm{mmol}$ of glucose and fructose, respectively. These results are depicted diagrammatically in Fig. 1. It is concluded that at these concentrations glucose and fructose stimulate water and sodium absorption equally per millimole of sugar absorbed.

$65 \mathrm{mM}$ glucose and $130 \mathrm{mM}$ fructose. These test solutions were designed so that glucose and fructose absorption rates would be approximately equal. Each of the three test solutions (mannitol, glucose, and fructose) contained $80 \mathrm{mM}$ sodium chloride, and the glucose solution also contained $65 \mathrm{mM}$ mannitol to achieve isotonicity.

The results are shown in Table I, part B. Glucose and fructose were absorbed at approximately equal rates. The stimulated rates of water and sodium absorption per millimole of sugar absorbed were about $30 \%$ lower with fructose than with glucose (Fig. 1 and Table I, part B), and the differences were statistically significant.

$30 \mathrm{mM}$ glucose and $40 \mathrm{mM}$ fructose. To study the effect of lower concentrations of sugars on water and sodium absorption, test solutions contained $120 \mathrm{mM}$ $\mathrm{NaCl}$ and either $40 \mathrm{mM}$ mannitol, $40 \mathrm{mM}$ fructose, or $30 \mathrm{mM}$ glucose plus $10 \mathrm{mM}$ mannitol. Table I, part C shows that the absorption rates of glucose and fructose were similar at about $7 \mathrm{mmol} / \mathrm{h}$. The stimulated water absorption rate was $13.2 \mathrm{ml} / \mathrm{mmol}$ with glucose and $13.3 \mathrm{ml} / \mathrm{mmol}$ with fructose $(P>0.4)$. The stimulated sodium absorption rates were $1.4 \mathrm{meq} / \mathrm{mmol}$ with 
TABLE I

Effect of Glucose and Fructose on Sodium and Water Movement



Number of studies: (A) 9, (B) 16, and (C) 9. If sugar concentrations in test solutions not equal, the difference was made up by mannitol.

In studies B and C mannitol movement assumed to be zero. Sodium concentrations are the mean of concentrations in fluid from proximal and distal ends of the 20 -cm test segment.

S, sugar; - absorption; +, secretion.

$*$ = Difference between glucose and fructose solution significant at $P<0.05$ by paired $t$ test.

$\ddagger$ Values in these columns were calculated by averaging the results in individual subjects. Hence, $\Delta \mathrm{Na}$ and $\Delta \mathrm{H}_{2} \mathrm{O}$ may not agree exactly with the ratio of averages of the same data.

glucose and $1.3 \mathrm{meq} / \mathrm{mmol}$ with fructose $(P>0.4)$. As shown in Fig. 1, these values were much higher than was noted in the previous two experiments (Table $I$, parts $A$ and $B$ ), and the difference is due to the higher sodium concentration in the perfusion solutions.

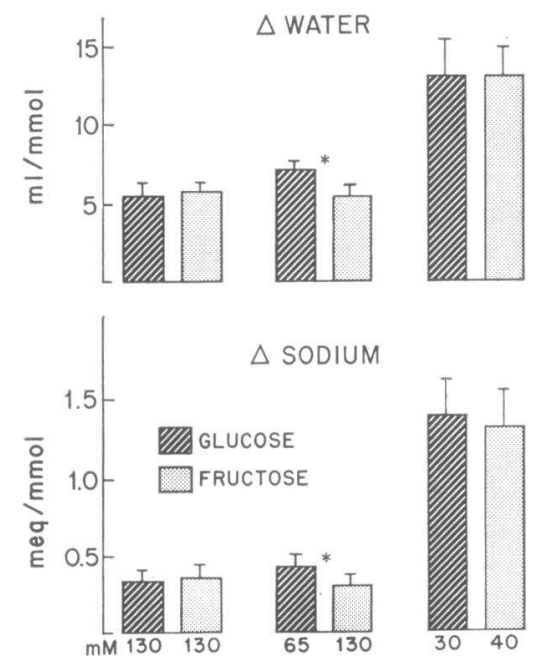

FIGURE 1 Rate of water and sodium absorption stimulated by the absorption of $1 \mathrm{mmol}$ of glucose and fructose. Water and sodium movement with mannitol was the base line. The concentrations of sugars for each of three sets of test solutions are shown at the bottom of the figure. The asterisk indicates $P<0.05$ by paired $t$ test.

\section{Effect of glucose and fructose on chloride movement}

This comparison was made with the test solutions containing $30 \mathrm{mM}$ glucose or $40 \mathrm{mM}$ fructose, and 120 $\mathrm{mM}$ sodium chloride, and the results are shown in Table II. Glucose and fructose stimulated chloride absorption to approximately the same extent and in proportion to the stimulated water and sodium absorption rates (compare with Table I, part C). None of the differences between fructose and glucose were statistically significant by paired $t$ test.

Chloride was also analyzed in 6 of the 16 studies reported in Table I, part B and the effects of glucose and fructose on chloride movement were similar to their influence on sodium movement, i.e., glucose stimulated more chloride absorption per millimole of sugar absorbed than did fructose.

\section{Effect of glucose and fructose on urea and potassium movement}

This comparison was made with the $65 \mathrm{mM}$ glucose and $130 \mathrm{mM}$ fructose solutions, which resulted in approximately equal rates of sugar absorption and showed that glucose was more effective than fructose in stimulating sodium and water absorption. Each of the three test solutions (mannitol, glucose, and fructose) contained urea and potassium (as $\mathrm{KCl}$ ) in amounts cal- 
TABLE II

Effect of Glucose and Fructose on Chloride Morement (Nine Studies)

\begin{tabular}{|c|c|c|c|c|c|}
\hline $\begin{array}{c}\text { Test } \\
\text { solution }\end{array}$ & $\begin{array}{l}\text { Net sugar } \\
\text { movement }\end{array}$ & {$[\mathrm{Cl}]$ Mean } & $\begin{array}{c}\text { Net } \mathrm{Cl} \\
\text { movement }\end{array}$ & \multicolumn{2}{|c|}{$\Delta \mathrm{Cl}$} \\
\hline & $\mathrm{mmol} / \mathrm{h} / 20 \mathrm{~cm}$ & meq/liter & $m e q / h / 20 \mathrm{~cm}$ & $m e q / h / 20 \mathrm{~cm}$ & meq' ${ }^{\prime} m o l$ \\
\hline $\begin{array}{r}\text { Mannitol } \\
40 \mathrm{mM}\end{array}$ & - & $118 \pm 1.2$ & $+1.0 \pm 1.4$ & - & - \\
\hline $\begin{array}{l}\text { Glucose } \\
\qquad 30 \mathrm{~m} \mathrm{M}^{*}\end{array}$ & $-6.7 \pm 0.9$ & $123 \pm 0.8$ & $-9.2 \pm 1.9$ & $-10.2 \pm 2.2$ & $-1.5 \pm 0.3$ \\
\hline $\begin{array}{l}\text { Fructose } \\
\qquad 40 \mathrm{mM}\end{array}$ & $-7.1 \pm 0.9$ & $122 \pm 1.9$ & $-7.9 \pm 1.4$ & $-8.9 \pm 1.4$ & $-1.3 \pm 0.2$ \\
\hline
\end{tabular}

* Plus $10 \mathrm{mM}$ mannitol to achieve isotonicity.

Mannitol absorption assumed to be zero.

- , net absorption; + , net secretion.

culated to achieve mean concentrations in the $20-\mathrm{cm}$ test segment approximately equal to their concentrations in plasma. As shown in Fig. 2, glucose and fructose both stimulated the absorption of water, sodium and urea, with glucose having a 20-30\% greater effect than fructose on the absorption of each of these substances. In contrast, glucose and fructose had opposite effects on potassium movement; glucose-stimulated potassium secretion, and fructose-stimulated potassium absorption. The luminal concentrations of potassium with mannitol, glucose, and fructose are shown in detail in Table III. Potassium concentrations in the test solutions were varied to compensate for different rates and directions of water movement with mannitol, glucose, and fructose (5), hoping to achieve approximately

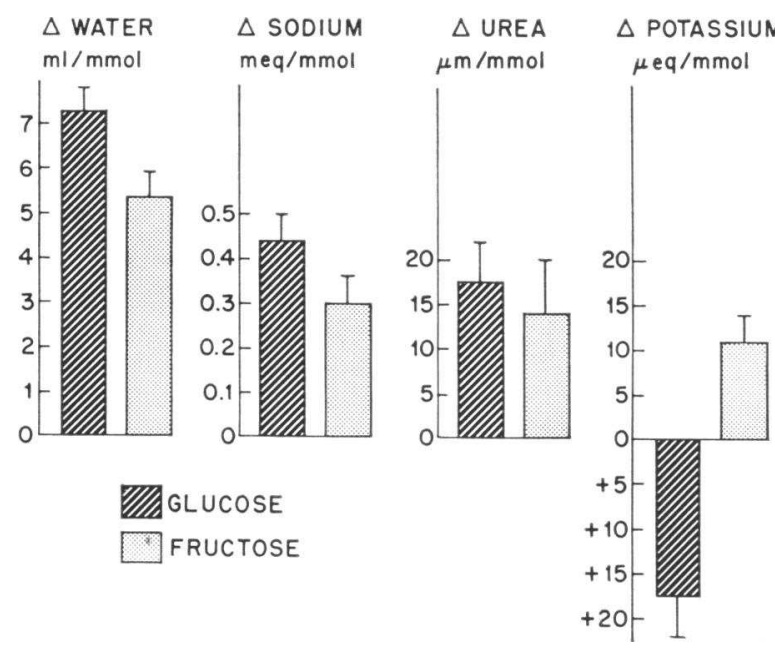

Figure 2 Effect of absorption of $1 \mathrm{mmol}$ of glucose and fructose on the net movement of water, sodium, urea, and potassium. Water and solute movement with mannitol was the base line. The plus signs indicate net secretion (accumulation in the lumen). equal mean potassium concentration in the $20-\mathrm{cm}$ test segment. With mannitol and fructose, potassium concentration fell progressively, whereas with glucose, it increased progressively between the infusion site and the end of the study segment. The potential difference (PD) across the mucosa was estimated from a comparison of luminal potassium concentration in the distal sample and serum potassium concentration by means of the Nernst equation, assuming that potassium movement is passive (8) and had reached equilibrium in accord with electrochemical gradients by the time the perfusion solution reached the distal sampling site (17). Calculated in this manner, PD was $2.2 \mathrm{mV}$ (mucosal side positive) with mannitol and fructose and $5.3 \mathrm{mV}$ (mucosal side negative) with glucose. According to these calculations, glucose produces a $7.5-\mathrm{mV}$ change in PD across the jejunal mucosa. This value is in good agreement with previous measurements of the effect of glucose on PD measured with an electrode $(5,13)$. Fructose, by contrast, had no effect on calculated PD, even though fructose stimulates almost as much water

TABLE III

Potassium_ Concentrations and Calculated PD from the Nernst Equation*

\begin{tabular}{|c|c|c|c|c|}
\hline \multirow{2}{*}{$\begin{array}{c}\text { Test } \\
\text { solutions }\end{array}$} & \multicolumn{3}{|c|}{ Potassium concentration } & \multirow[b]{2}{*}{ PD } \\
\hline & Infusion & Proximal & Distal & \\
\hline & & meq/liter & & $m V$ \\
\hline \multicolumn{5}{|l|}{ Mannitol } \\
\hline $130 \mathrm{~m} \mathrm{M}$ & $5.17 \pm 0.04$ & $4.65 \pm 0.15$ & $4.11 \pm 0.08$ & $+2.2 \pm 1.2$ \\
\hline \multicolumn{5}{|l|}{ Glucose } \\
\hline $65 \mathrm{mM}$ & $3.80 \pm 0.08$ & $4.84 \pm 0.17$ & $5.41 \pm 0.18$ & $-5.3 \pm 0.8$ \\
\hline \multicolumn{5}{|l|}{ Fructose } \\
\hline $130 \mathrm{mM}$ & $4.45 \pm 0.04$ & $4.32 \pm 0.11$ & $4.11 \pm 0.15$ & $+2.2 \pm 1.0$ \\
\hline
\end{tabular}

* PD was calculated in individual subjects by the following equation: $\mathrm{PD}=61.5 \times \log$ serum $[\mathrm{K}] /$ lumen $[\mathrm{K}]$. A minus sign means the lumen is negative to the serosa, and vice versa. 


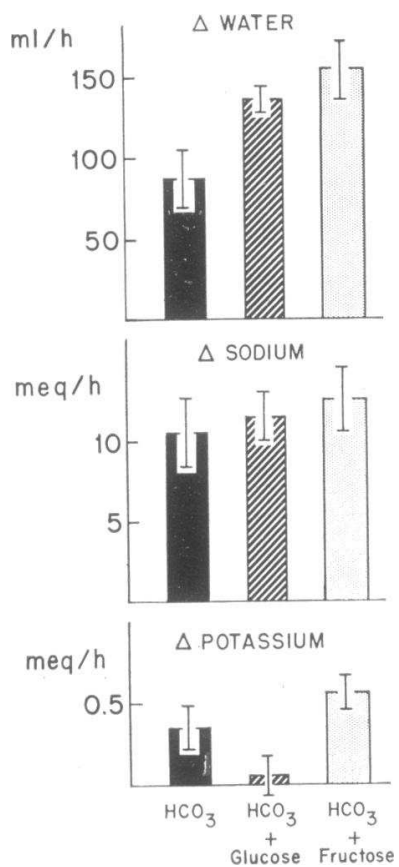

FIGURE 3 Effect of bicarbonate alone, bicarbonate plus glucose, and bicarbonate plus fructose on water, sodium, and potassium movement. The base-line solution contained mannitol and sulfate, and the bicarbonate solution contained mannitol.

and sodium absorption as glucose (Fig. 2). Qualitatively similar results were noted with the other pairs of sugar concentrations that were studied and reported in Table I.

Effect of bicarbonate, bicarbonate plus glucose, and bicarbonate plus fructose

In all results presented so far, chloride was the only anion in the perfused solutions. The results showed that jejunal perfusion of $65 \mathrm{mM}$ glucose and $130 \mathrm{mM}$ fructose resulted in approximately equal rates of sugar absorption, and only with this set of test solutions was glucose more effective than fructose in stimulating water and sodium absorption. These sugar concentrations were selected for further study in experiments designed to assess the interaction of bicarbonate and sugars on water, sodium, and potassium movement.

Four test solutions were perfused in each of 10 subjects. One contained mannitol and sodium sulfate (this was the reference solution). The second contained 70 $\mathrm{meq} /$ liter of bicarbonate to replace the sulfate. The third and fourth contained $70 \mathrm{meq} /$ liter of bicarbonate plus either $65 \mathrm{mM}$ glucose or $130 \mathrm{mM}$ fructose. All test solutions were isotonic to plasma and contained $80 \mathrm{meq} / \mathrm{liter}$ of sodium and $5 \mathrm{mM}$ potassium chloride. The stimulatory effects of bicarbonate and bicarbonate plus the sugars were calculated exactly as demonstrated in Table I, and the results are shown in Fig. 3. The addition of bicarbonate stimulated the absorption of $87 \mathrm{ml} / \mathrm{h}$ water, $10.4 \mathrm{meq} / \mathrm{h}$ of sodium, and $0.3 \mathrm{meq} / \mathrm{h}$ of potassium. (See Table IV for bicarbonate absorption rates with mannitol, glucose and fructose.) When, in addition to the absorption of bicarbonate, $17 \mathrm{mmol} /$ $\mathrm{h}$ glucose or $21 \mathrm{mmol} / \mathrm{h}$ fructose were absorbed, water absorption was stimulated further, to $135 \mathrm{ml} / \mathrm{h} \quad(P<$ $0.005)$ and $155 \mathrm{ml} / \mathrm{h}(P<0.05)$, respectively. In contrast, absorption of glucose and fructose did not significantly enhance sodium absorption (above that noted with bicarbonate alone). Glucose depressed $(P<0.05)$ and fructose enhanced $(P<0.05)$ the stimulated potassium absorption that was noted with bicarbonate alone.

Effect of chloride, bicarbonate, and sulfate anions on glucose-stimulated water and sodium absorption

The data in the previous section demonstrated that glucose and fructose had no significant effect on sodium movement when bicarbonate was the major anion present in the perfusing solution. To evaluate further the importance of the anionic composition of test solutions on glucose-stimulated absorption, four sets of experiments were carried out. Each set consisted of a comparison of the effect of $65 \mathrm{mM}$ glucose and mannitol on sodium and water absorption. In the first set, chloride was the only anion present. In the second, chloride and bicarbonate were equal at $40 \mathrm{meq} / \mathrm{liter}$. In the third, bicarbonate was 70 and chloride was $10 \mathrm{meq} /$ liter, and in the fourth set chloride and bicarbonate were completely replaced by sulfate. In each of the sets



FIGURE 4 Effect of anion composition on net water and sodium absorption stimulated by the absorption of $1 \mathrm{mmol}$ of glucose. Water and sodium movement with mannitol was the base line. Total anion concentration was $80 \mathrm{meq} / \mathrm{liter}$ with all solutions. The $\mathrm{Cl}+\mathrm{HCO}_{3}$ solution contained 40 meq/liter of each anion. 
TABLE IV

Effect of Glucose and Fructose on Bicarbonate Morement

\begin{tabular}{lccc}
\hline Test solutions* & Net S $\ddagger$ & $\begin{array}{c}{\left[\mathrm{HCO}_{3}\right]} \\
\text { Mean }\end{array}$ & Net $\mathrm{HCO}_{3} \ddagger$ \\
\hline & $m m o l / h / 20 \mathrm{~cm}$ & meq/liter & $m e q / h / 20 \mathrm{~cm}$ \\
(A) $70 \mathrm{meq} /$ liter & Bicarbonate, $n=10$ & \\
Mannitol & - & $29 \pm 3$ & $-9.0 \pm 0.9$ \\
Glucose & $-17 \pm 1.3$ & $44 \pm 3$ & $-10.6 \pm 0.9$ \\
Fructose & $-21 \pm 2.5$ & $44 \pm 2$ & $-11.1 \pm 1.6$ \\
(B) 40 meq/liter & Bicarbonate, $n=13$ & \\
Mannitol & - & $16 \pm 1$ & $-4.8 \pm 0.8$ \\
Glucose & $-18 \pm 1$ & $24 \pm 1$ & $-5.9 \pm 0.9$ \\
Fructose & $-21 \pm 2$ & $20 \pm 1$ & $-5.8 \pm 0.9$ \\
\hline
\end{tabular}

* Sodium concentration in $\mathrm{A}$ and $\mathrm{B}$ test solutions $=80$ meq/liter.

Glucose concentration $=65 \mathrm{mM}$; fructose concentration $=130 \mathrm{mM}$.

$\ddagger-$, net absorption.

of experiments the sodium concentration was $80 \mathrm{meq} /$ liter, and all solutions had an osmolality of $290 \mathrm{mosmol} /$ $\mathrm{kg}$.

The results of these experiments are shown in Fig. 4. They demonstrate that glucose has progressively less effect on sodium and water absorption as the chloride concentration is reduced by substitution of either bicarbonate or sulfate.

Effect of glucose and fructose on bicarbonate absorption

As shown in Table IV, neither glucose nor fructose significantly enhanced bicarbonate absorption in spite of the fact that both sugars stimulated water absorption (Fig. 3). This suggests that solvent drag has no effect on bicarbonate movement in the human jejunum. Since bicarbonate absorption was the same in the presence of glucose and fructose and since these sugars have different effects on transmembrane PD (Table III), bicarbonate movement is apparently not affected by electrical gradients. However, bicarbonate absorption is influenced by concentration gradients, as illustrated by the fact that absorption rate was almost twice as rapid when luminal bicarbonate concentration was 29-44 meq/liter as when luminal concentration was 1624 meq/liter (Table IV).

Absolute rates of sodium and water movement with various glucose-containing solutions

In previous sections of this paper the effect of sugars has been expressed in terms of a stimulated absorption rate relative to a control solution containing mannitol. This is necessary to show the effect of the sugars, but the results may be misleading in certain situations, particularly if the mannitol base-line values are different with different solutions. For example, assume that glucose reduced water secretion rate from 100 to $50 \mathrm{ml} / \mathrm{h}$ with solution $\mathrm{A}$ and stimulated absorption from 100 to $150 \mathrm{ml} / \mathrm{h}$ with solution $\mathrm{B}$. The glucose effect is $50 \mathrm{ml} / \mathrm{h}$ with both solutions, but this result fails to convey the fact that in the presence of glucose the jejunum was secreting with solution $\mathrm{A}$ and $\mathrm{ab}-$ sorbing with solution $B$. Therefore, in Table $V$ the results of various solutions containing glucose are shown in terms of absolute absorption or secretion rates. When the test solution contained $80 \mathrm{meq} / \mathrm{liter}$ sodium and $65 \mathrm{mM}$ glucose, sodium was absorbed only if chloride was the predominant anion, although water was absorbed with the sulfate and bicarbonate-containing solutions. When sodium and chloride concentrations were kept at $80 \mathrm{meq} / \mathrm{liter}$ and glucose concentration increased to $130 \mathrm{mM}$, sodium absorption rate increased from 2 to $4 \mathrm{meq} / \mathrm{h}$ and water absorption increased from 97 to $143 \mathrm{ml} / \mathrm{h}$. Highest sodium absorption rates occurred when the sodium and chloride concentrations were increased to $120 \mathrm{meq} / \mathrm{liter}$ and the glucose concentration was reduced to $30 \mathrm{mM}$.

\section{DISCUSSION}

Most intestinal preparations absorb water and this water flow theoretically could drag sodium chloride and other solutes with it. However, relatively few experiments have been conducted to evaluate the extent to which solvent drag actually does influence salt transport. Green, Seshadri, and Matty (18) found that net absorption and unidirectional flux of sodium was not reduced when water absorption in the proximal small intestine $^{1}$ of the rat in vitro was stopped by placing

\section{TABLE V}

Comparison of the Makeup Infusion Solution on Absolute Rates of Sodium and Water Movement in the Presence of Glucose

\begin{tabular}{rrrrr}
\hline \multicolumn{3}{c}{ Test solution } & & \\
\cline { 1 - 3 }$[\mathrm{Na}]$ & [Glucose] & $\begin{array}{l}\text { Major } \\
\text { anion }\end{array}$ & Net $\mathrm{Na}^{*}$ & Net $\mathrm{H}_{2} \mathrm{O}^{*}$ \\
\hline meq/liter & $m M$ & & $m e q / h / 20 \mathrm{~cm}$ & $m l / h / 20 \mathrm{~cm}$ \\
80 & 65 & $\mathrm{SO}_{4}$ & $+10 \pm 0.6$ & $-16 \pm 7$ \\
80 & 65 & $\mathrm{HCO}_{3}$ & $+2 \pm 0.9$ & $-64 \pm 7$ \\
80 & 65 & $\mathrm{HCO}_{3} / \mathrm{Cl}$ & $0 \pm 1.3$ & $-72 \pm 12$ \\
80 & 65 & $\mathrm{Cl}$ & $-2 \pm 1.0$ & $-97 \pm 9$ \\
80 & 130 & $\mathrm{Cl}$ & $-4 \pm 1.6$ & $-143 \pm 20$ \\
120 & 30 & $\mathrm{Cl}$ & $-9 \pm 1.8$ & $-88 \pm 18$ \\
\hline
\end{tabular}

* -, absorption; + , secretion.

1 Reference 18 reports studies exclusively in the proximal small intestine in spite of its title, which suggests that the experiments were carried out in the lower small bowel. 
hypertonic mannitol in the mucosal solution. This experiment and others reported by Schultz and $\mathrm{Za}$ lusky (19) and Schultz, Zalusky, and Gass (20) in in vitro rabbit ileum were interpreted originally and in subsequent reviews $(1,21)$ as indicating that solvent drag is probably not a major mechanism of sodium or chloride absorption. Starting in 1965, a series of experiments by Fordtran, Rector, and associates (22, $23,5,13$ ) were reported which suggested that solvent drag was a major mechanism for sodium chloride absorption in the proximal but not in the distal small bowel of normal human subjects. Our data suggested that the entire increment in sodium absorption in response to glucose could, in the human jejunum, be explained as a passive consequence of solvent flow (5, 24). Although it was specifically pointed out that active sodium transport might also play a role (reference 5, p. 898), criteria for active sodium absorption in the human jejunum could not be met.

Our conclusion that solvent drag was a major mechanism for sodium absorption in the human jejunum was questioned by Schultz and Curran $(25,26)$. While recognizing that our data were compatible with our solvent flow model, Schultz and Curran (26) pointed out that the results of Holdsworth and Dawson (27) and Sladen and Dawson (28) were in major disagreement with our results and were exceedingly difficult to reconcile with our solvent drag model. They favored the concept of a direct link between sodium, sugar, and a transport site in the brush border membrane as the mechanism by which glucose stimulates sodium absorption in the human jejunum. I agree that the experimental results of Holdsworth and Dawson and Sladen and Dawson $(27,28)$ are difficult to reconcile with data obtained previously in this laboratory. ${ }^{2}$ The only explanation I can offer is that the perfusion methods they used in these particular experiments may not reliably measure net water and sodium movement (29-31).

More recently, Modigliani and Bernier (15) concluded that the effect of glucose on net sodium movement in the jejunum could be accounted for by both solvent drag and stimulation of active sodium absorption, and this conclusion was accepted by Schultz, Frizzell, and Nellans (4). However, the extent to which these two mechanisms actually contribute to the net enhancement of sodium and water absorption by

\footnotetext{
2 The results of Holdsworth and Dawson (27) also disagree with data obtained in the present paper. For example, they found that with $2.5 \%$ solutions $(140 \mathrm{mM})$ of glucose and fructose, water absorption was 2.5 times higher with glucose than with fructose per gram of sugar absorbed (their Table II) ; in contrast, with $130 \mathrm{mM}$ sugar solutions we found water absorption was equal with glucose and fructose per millimole of sugar absorbed (Table I, this paper).
}

actively transported sugars is not known, and there is no way to guess from previous work whether active sodium transport (or solvent drag) accounts for 1, 50, or $99 \%$ of the observed response.

The major purpose of the present series of experiments was to estimate the relative importance of these two mechanisms by comparing water and sodium movements with mannitol, fructose, and glucose. The results conclusively demonstrate that fructose stimulates sodium absorption in the human jejunum, compared with the rate of sodium movement when fructose is replaced by a nonabsorbable solute (mannitol). Since previous studies have not suggested an interaction of fructose and sodium with a common carrier $(9,10)$ it seems likely that the effect of fructose is mediated passively by solvent flow. The fact that fructose stimulates urea and potassium absorption is further evidence in favor of a passive connection between fructose and sodium absorption. These results thus strengthen our previous suggestion that solvent flow stimulates sodium absorption in the human jejunum.

Since glucose and fructose are both absorbed by carrier-mediated processes located in the brush border membrane, it is reasonable to assume that glucose absorption stimulates the same amount of passive water and sodium absorption as fructose, per millimole of sugar absorbed (see Introduction). However, two pieces of evidence indicate that glucose also stimulates active sodium absorption in the human jejunum. First, when glucose and fructose absorption rates are $21-24 \mathrm{mmol} / \mathrm{h}$ (Table I, part B), glucose stimulates significantly more sodium chloride and water absorption than fructose. $^{3}$ Assuming that the effect of fructose is passive and that glucose has the same passive consequence as fructose, it seems reasonable to conclude that under these experimental conditions each millimole of absorbed glucose stimulates the absorption by solvent drag of $0.29 \mathrm{meq}$ of sodium and $5.4 \mathrm{ml}$ of water (equal to the fructose effect). In addition, each millimole of absorbed glucose stimulated the absorption of 0.15 meq of sodium and $1.9 \mathrm{ml}$ of water (the difference between the fructose and the glucose effects), and this component may be assumed to be secondary to stimulation of active sodium transport. The apparent sodium concentration in the active component $(0.15 \mathrm{meq}$ sodium and $1.9 \mathrm{ml}$ water) of the stimulated absorbate is $79 \mathrm{meq} / \mathrm{liter}$ This is fairly close to the sodium concentration in the luminal contents ( $88 \mathrm{meq} / \mathrm{liter})$. For the passive component $(0.29 \mathrm{meq}$ sodium and $5.4 \mathrm{ml}$ water $)$, the concentration of sodium in the stimulated absorbate is 54 meq/liter. Since the luminal sodium concentration in

\footnotetext{
${ }^{3}$ In this instance our results are in qualitative agreement with those of Holdsworth and Dawson (27) and Sladen and Dawson (28).
} 
these studies was about $95 \mathrm{meq} /$ liter, there was a moderate sieving out of sodium through the solvent flow pathway, consistent with previous estimates of the reflection coefficient for sodium chloride in the human jejunum $(5,22)$.

The second piece of evidence indicating that glucose stimulates active sodium absorption comes from the study of the effect of these sugars on potassium movement. Although glucose and fructose have qualitatively similar effects on water, sodium, and urea movement, these sugars have opposite effects on potassium (Fig. 2). Since potassium movement is generally assumed to be passive (8), and since the opposite effects of glucose and fructose cannot be explained by differences in luminal potassium concentration (Table III), glucose stimulation of potassium secretion suggests that glucose absorption generates a lumen-negative PD across the jejunal mucosa. The fact that fructose stimulates almost as much water and sodium absorption as glucose, but stimulates potassium absorption rather than secretion, indicates that solvent drag does not generate a similar PD change. In fact, fructosestimulated water and sodium absorption does not cause the PD to change at all according to estimates based on the Nernst equation and the potassium concentration in fluid aspirated from the distal end of a 20 -cm distal segment (Table III).

Therefore, glucose stimulates both active and passive sodium transport in the jejunum, and the relative importance of these two mechanisms in the overall net enhancement of sodium absorption apparently depends on the sugar and sodium concentrations in the jejunal lumen. For example, when a $130 \mathrm{mM}$ sugar and $80 \mathrm{mM} \mathrm{NaCl}$ solution was perfused, glucose and fructose stimulated sodium and water absorption equally per millimole of sugar absorbed, suggesting that the entire enhancement of net sodium absorption was passive, secondary to solvent drag. A similar conclusion was reached with $30 \mathrm{mM}$ sugar and $120 \mathrm{mM} \mathrm{NaCl}$ solution (Fig. 1). These results indicate that glucose stimulation of active sodium absorption was manifested only by the generation of a PD across the mucosa. In other words, glucose stimulated active sodium absorption, and this generated a PD that caused sodium (and potassium) secretion; net sodium movement was not affected. A similar mechanism probably explains why glucose in the human ileum increases transmucosal PD $(5,14)$ and increases unidirectional sodium flux rates from lumen to plasma and from plasma to lumen (15) but has no effect on net sodium absorption $(5,15,16)$.

In only one of our test solutions (Table I, part B) did glucose induce a greater stimulation of net sodium absorption than fructose per millimole of sugar absorbed and even here fructose was $66 \%$ as effective as glucose (Fig. 1)." I therefore conclude that solvent drag is quantitatively the most important mechanism by which glucose stimulates net sodium absorption in the human jejunum. Glucose stimulation of active sodium absorption is, for the most part, nullified by passive sodium excretion in response to the electrical gradients generated by active sodium pumping. Of course, if the intestine were studied under experimental conditions that short-circuited the PD, glucose stimulation of active sodium transport would contribute in a major way to the observed increase in net sodium absorption (32).

Another purpose of these experiments was to determine whether or not glucose and bicarbonate are additive in their stimulatory effects on net sodium absorption. With test solutions in which bicarbonate was virtually the only anion present in the luminal fluid, bicarbonate and glucose were found to be additive insofar as stimulation of water absorption is concerned, but net sodium absorption stimulated by bicarbonate was not further enhanced by the addition of glucose or fructose. These results suggest that the solvent flow pathway markedly restrict the movement of sodium bicarbonate. Further studies showed that the accompanying anion determines the degree to which sugars stimulate sodium absorption $\left(\mathrm{Cl}>\mathrm{SO}_{4}>\mathrm{HCO}_{3}\right)$.

A final point of physiologic interest concerns the absorption of bicarbonate. It is known from previous work that bicarbonate absorption in the human jejunum is an active process (13), that bicarbonate movement is minimally affected by solvent drag (5), and that absorption rate increases in response to increasing luminal bicarbonate concentrations between 0 and 60 meq/liter (13). Although bicarbonate absorption is, therefore, sensitive to concentration gradients across the mucosa, the present studies show that bicarbonate absorption is not influenced by electrical gradients. This is most dramatically illustrated by the fact that glucose stimulates a PD (mucosal side negative) that induces potassium and sodium secretion but does not accelerate absorption of the bicarbonate anion.

From the practical standpoint of designing oral sugar solutions for therapy of diarrheal diseases, several conclusions seem justified from these results. First, glucose is preferable to fructose since under certain conditions glucose stimulates more absorption of sodium and water than fructose per millimole of sugar absorbed. Furthermore, glucose is more rapidly absorbed than fructose

${ }^{4}$ The reason why glucose was more effective than fructose with one but not with two other test solutions is not entirely clear, but it indicates that the quantitative jejunal response to glucose in terms of enhancing sodium and water absorption is complicated and is determined by absolute rates of sugar absorption as well as by the concentration of sodium in the luminal contents. 
at sugar concentrations likely to be employed in oral test solutions. Consequently, a given rate of sugar absorption can be obtained with a lower glucose concentration, leaving room to elevate the sodium concentration and still keep the solution isotonic with plasma. The disadvantage of glucose (compared to fructose) is that the electrical gradients it generates tends to stimulate potassium secretion, whereas fructose stimulates potassium absorption. Second, the sodium concentration in the jejunal lumen is of critical importance in determining the rate of sugar enhancement of sodium absorption. For example, when the luminal sodium concentration was $120 \mathrm{meq} / \mathrm{liter}$, sodium absorption was more than twice as fast as when the luminal sodium concentration was $80 \mathrm{meq} / \mathrm{liter}$ (Table V). It would seem worthwhile to evaluate whether maltose or starch could partially replace glucose in oral test solutions; if so, higher sodium concentrations could be used without exceeding the lower limits of sugar requirement or the upper limits of tolerable hypertonicity. Third, if the major purpose of oral glucose solutions is to stimulate sodium absorption, chloride should be the only anion. Of course, some patients are severely acidotic, and bicarbonate may be needed to correct this acid-base abnormality. And finally, caution must be exercised in extrapolating these results with a $20-\mathrm{cm}$ test segment to an intact patient who has approximately $120 \mathrm{~cm}$ of proximal small intestine capable of responding to glucose by enhancing its rate of net sodium absorption. For example, the fact that sodium absorption is more than twice as rapid with a $30 \mathrm{mM}$ glucose and $120 \mathrm{meq} /$ liter $\mathrm{NaCl}$ solution than with solutions containing $130 \mathrm{mM}$ glucose and $80 \mathrm{meq} /$ liter $\mathrm{NaCl}$ does not necessarily mean that qualitatively similar results would be obtained if absorption over a longer segment of intestine were studied.

\section{ACKNOWLEDGMENTS}

The author is grateful for the generous support and teaching of Floyd Rector. Stephen Morawski, Martha Hicks, Vicki Jones, Barbara Bailey, and Jean Harber gave expert assistance which is deeply appreciated.

This work was supported by research grant 5 RO1 AMO6506 from the National Institute of Arthritis, Metabolism and Digestive Diseases.

\section{REFERENCES}

1. Schultz, S. G., and P. F. Curran. 1968. Intestinal absorption of sodium chloride and water. Handb. Physiol. 3(Sect. 6) : 1245-1275.

2. Schultz, S. G., and P. F. Curran. 1970. Coupled transport of sodium and organic solutes. Physiol. Rev. 50: 637-718.

3. Schultz, S. G., and R. A. Frizzell. 1972. An overview of intestinal absorption and secretory processes. Gastroenterology. 63: 161-170.
4. Schultz, S. G., R. A. Frizzell, and H. N. Nellans. 1974. Ion transport by mammalian small intestine. Annu. Rev. Physiol. 36: 51-91.

5. Fordtran, J. S., F. C. Rector, Jr., and N. W. Carter. 1968. The mechanisms of sodium absorption in the human small intestine. J. Clin. Invest. 47: 884-900.

6. Fordtran, J. S., and W. Locklear. 1966. Ionic constituents and osmolality of gastric and small-intestinal fluids after eating. Am. J. Dig. Dis. 11: 503-521.

7. Pierce, N. F., J. G. Banwell, R. C. Mitra, G. J. Caranasos, R. I. Keimowitz, A. Mondal, and P. M. Manji. 1968. Effect of intragastric glucose-electrolyte infusion upon water and electrolyte balance in Asiatic cholera. Gastroenterology. 55: 333-343.

8. Turnberg, L. A. 1971. Potassium transport in the human small bowel. Gut. 12: 811-818.

9. Schultz, S. G., and C. K. Strecker. 1970. Fructose influx across the brush border of rabbit ileum. Biochim. Biophys. Acta. 211 : 586-588.

10. Guy, M. J., and J. J. Deren. 1971. Selective permeability of the small intestine for fructose. Am. J. Physiol. 221 : 1051-1056.

11. Holdsworth, C. D., and A. M. Dawson. 1965. Absorption of fructose in man. Proc. Soc. Exp. Biol. Med. 118: $142-145$.

12. Cook, G. C. 1969. Absorption products of $\mathrm{D}(-)$ fructose in man. Clin. Sci. (Oxf.). 37: 675-687.

13. Turnberg, L. A., J. S. Fordtran, N. W. Carter, and F. C. Rector, Jr. 1970. Mechanism of bicarbonate absorption and its relationship to sodium transport in the human jejunum. J. Clin. Invest. 49: 548-556.

14. Turnberg, L. A., F. A. Bieberdorf, S. G. Morawski, and J. S. Fordtran. 1970. Interrelationships of chloride, bicarbonate, sodium and hydrogen transport in the human ileum. J. Clin. Invest. 49: 557-567.

15. Modigliani, R., and J. J. Bernier. 1972. Effects of glucose on net and unidirectional movements of water and electrolytes in the human small intestine. Biol. GastroEnterol. 5: 165.

16. Saltzman, D. A., F. C. Rector, Jr., and J. S. Fordtran. 1972. The role of intraluminal sodium in glucose absorption in vivo. J. Clin. Invest. $51: 876-885$.

17. Bieberdorf, F. A., P. Gorden, and J. S. Fordtran. 1972. Pathogenesis of congenital alkalosis and diarrhea. Implications for the physiology of normal ileal electrolyte absorption and secretion. J. Clin. Invest. 51: 19581968.

18. Green, K., B. Seshadri, and A. J. Matty. 1962. Independence of transfer of solute and solvent across the rat ileum. Nature (Lond.). 196: 1322-1323.

19. Schultz, S. G., and R. Zalusky. 1964. Ion transport in isolated rabbit ileum. I. Short-circuit current and $\mathrm{Na}$ fluxes. J. Gen. Physiol. 47: 567-584.

20. Schultz, S. G., R. Zalusky, and A. E. Gass, Jr. 1964. Ion transport in isolated rabbit ileum. III. Chloride fluxes. J. Gen. Physiol. 48: 375-378.

21. Curran, P. F. 1965. Ion transport in intestine and its coupling to other transport processes. Fed. Proc. 24: 993-999.

22. Fordtran, J. S., F. C. Rector, Jr., M. F. Ewton, N. Soter, and J. Kinney. 1965. Permeability characteristics of the human small intestine. J. Clin. Invest. 44: 19351944.

23. Fordtran, J. S., F. C. Rector, Jr., T. W. Locklear, and M. F. Newton. 1967. Water and solute movement in 
the small intestine of patients with sprue. J. Clin. Invest. 46: $287-298$.

24. Fordtran, J. S., and F. C. Rector, Jr. 1971. Stimulation of intestinal sodium absorption by sugars. Am. J. Clin. Nutr. 24: 503-504.

25. Schultz, S. G., and P. F. Curran. 1970. Stimulation of intestinal sodium absorption by sugars. Am. J. Clin. Nutr. 23: 437-440.

26. Schultz, S. G., and P. F. Curran. 1971. Stimulation of intestinal sodium absorption by sugars: reply to Dr. Fordtran. Am. J. Clin. Nutr. 24: 504-505.

27. Holdsworth, C. D., and A. M. Dawson. 1964. The absorption of monosaccharides in man. Clin. Sci. (Oxf.). 27 : 371-379.

28. Sladen, G. E., and A. M. Dawson. 1969. Interrelation- ships between the absorptions of glucose, sodium and water by the normal human jejunum. Clin. Sci. (Oxf.). 36: 119-132.

29. Fordtran, J. S. 1969. Segmental perfusion techniques. Gastroenterology. 56: 987-989.

30. Soergel, K. H. 1969. An evaluation of perfusion techniques in the study of water and electrolyte absorption in man: the problem of endogenous secretions. Gut. 10: 601.

31. Modigliani, R., and J. J. Bernier. 1971. Absorption of glucose, sodium, and water by the human jejunum studied by intestinal perfusion with a proximal occluding balloon and at variable flow rates. Gut. 12: 184-193.

32. Binder, H. J. 1974. Sodium transport across isolated human jejunum. Gastroenterology. 67: 231-236. 